\title{
STATUS ASSESSMENT OF AGRICULTURAL DRAINAGE DITCHES
}

\author{
D. Avilés, I. Wesström, A. Joel
}

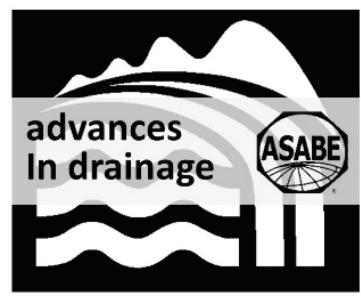

\begin{abstract}
Poor maintenance, environmental concerns, land use changes, and adaptation to climate change are creating a growing need for better agricultural drainage. The objectives of this study were to identify ditch properties that can be evaluated visually on-site and related soil erosion processes, and to define parameters requiring more intensive study and estimate these using simplified methods. The study included surveys of ditches in various soils using MADRAS (Minnesota Agricultural Ditch Research Assessment for Stability) to classify ditch status. To explain why some ditch segments were in poor condition, additional field and laboratory studies were carried out. Soil samples were taken for analysis of particle size distribution, unsaturated direct shear strength, and critical stress for erosion. The HEC-RAS data model was used for simulation of hydraulic forces acting at different flow rates. Digital maps of land use in the catchment area in different years were used to estimate changes in runoff conditions over time. MADRAS proved to be a suitable tool for rapid assessment of stability problems in ditches. The HEC-RAS simulations were a good complement to MADRAS in assessing how changes in land use affected the hydraulic load and in highlighting bottlenecks in the system. However, the hydraulic load did not adequately explain the degree of degradation in some ditch segments. Measurements of soil shear strength were a good aid to understanding existing degradation. Thus, assessment of soil erodibility and bank stability is essential in anticipating the risk of future erosion processes in ditches.
\end{abstract}

Keywords. Cohesive strength meter, HEC-RAS, MADRAS, Unsaturated direct shear strength.

A well-drained soil is one of the most important prerequisites for rational agricultural production and for maintaining soil production capacity. However, drainage operations can lead to major environmental problems in surface water bodies, such as increased nutrient loads, rapid runoff during some periods, and biodiversity losses, which in many cases prevent the water body from being classified as having good ecological status. Moreover, open main drains and culverts must be regularly maintained in order to safeguard their capacity to conduct water, e.g., maintenance is necessary to remove woody vegetation and deposited sediment, stabilize bank slopes, and address toe scour problems (Fausey et al., 1982). These routine maintenance activities are costly, disrupt the existing ecology, and adversely affect water quality (Kallio et al., 2010). Thus, there is increasing conflict between demands to maintain ditches and demands to protect the environment.

Neglected maintenance, environmental concerns, land use changes, and adaptation to climate change are the main

Submitted for review in February 2017 as manuscript number NRES 12307; approved for publication as part of the "Advances in Drainage: Selected Works from the 10th International Drainage Symposium" collection by the Natural Resources \& Environmental Systems Community of ASABE in November 2017.

The authors are Daniel Avilés, Doctoral Student,Swedish University of Agricultural Sciences. Ingrid Wesström, Associate Professor, and Abraham Joel, Associate Professor, Department of Soil and Environment, Swedish University of Agricultural Sciences, Uppsala, Sweden. Corresponding author: Ingrid Wesström, Swedish University of Agricultural Sciences, P.O. Box 7014, SE-750 07 Uppsala, Sweden; phone: +46-18-671183; e-mail: Ingrid.Wesstrom@slu.se. issues currently associated with agricultural land drainage. Some ditches in the countryside are stable, while others require large sums of money for maintenance. Unstable ditches can generate significant quantities of sediment, which degrade the hydraulic capacity and water quality of the ditch and often lead to eutrophication downstream (Magner et al., 2010). This means that a ditch could be converted from a recipient to a source of nutrients. Furthermore, insufficient hydraulic capacity can also be due to changes in the flow regime caused by changes in land use and climate. When insufficient capacity leads to inundation, the adjacent land also becomes a contributor of nutrients to the water body.

Measurements of soil strength are necessary to achieve a more accurate assessment of ditch status, understand the reasons behind ditch instability, and propose remedial measures. The processes leading to bank erosion include weathering processes (i.e., air temperature, freeze-thaw cycles, and wetting-drying cycles), fluid forces, and mass failure (Lawler, 1993). There is an acknowledged need to relate soil physical properties to resistance to erosion under these processes (Knapen et al., 2007). For example, Constantine et al. (2009) related soil resistance to erosion and the physical properties of the bank material, opening up the possibility to develop procedures that use soil physical characteristics to assess soil susceptibility to bank erosion. However, erodibility values are not known for a large number of the different soils in Sweden, so it is difficult to relate estimated shear forces induced by flowing water to actual soil strength. Therefore, more studies are necessary on soil erodibility and the shear strength of undisturbed soils. 
The overall aim of this study was to develop tools that could be helpful in implementing appropriate drain maintenance measures and, in the long term, in achieving stable ditches with reduced maintenance needs. Specific objectives were to identify ditch properties that can be evaluated visually on-site and the soil erosion processes they represent, and to define parameters that need more intensive study and suggest methods for their estimation.

\section{MATERIAL AND Methods}

Different sizes of ditch reaches in various soils were studied. MADRAS (Minnesota Agricultural Ditch Research Assessment for Stability) was used to classify the status of the ditches (Magner et al., 2010). The assessment included classification of bank stability (i.e., the presence of erosion from surface runoff and seepage), widening or undercutting of cross-sections, and sediment deposition on the ditch base. Based on field observations, every ditch segment was scored based on its status. To explain why some ditch segments were in poor condition, additional studies were carried out in the field and the laboratory. For characterization of soil sensitivity to erosion and bank stability, soil samples were taken for analysis of particle size distribution, near-saturation shear strength (unsaturated direct shear test), and critical stress for erosion. The data model HEC-RAS (Hydrologic Engineering Center's River Analysis System; USACE, 2010) was used for simulation of the hydraulic forces acting at different flow rates. Ditch design blueprints were used as input data for cross-sections. Digital maps of land use in the catchment area from different years were used to estimate changes in runoff conditions over time.

\section{FIELD SITE}

The catchment used for the study is located $5 \mathrm{~km}$ south of Uppsala, Sweden (59 48' 23.312" N; $\left.17^{\circ} 39^{\prime} 51.726^{\prime \prime} \mathrm{E}\right)$ and has an area of 720 ha. Mean annual temperature at the site is $5.5^{\circ} \mathrm{C}$ (data from Ultuna 1961-1990), but four months of the year (December to March) have mean temperatures below $0^{\circ} \mathrm{C}$ (Alexandersson et al., 1991). Mean annual precipitation is $528 \mathrm{~mm}$. To the northwest, the landscape is dominated by forest, and the soil consists of post-glacial sand deposits. To the east, there is predominantly farmland and other open land on well-aggregated silty clay to clay soil (45\% to $60 \%$ clay), with parent material consisting of post-glacial sedimentary clay. The land use is dominated by agriculture, but there are also urban settlements within the area that have expanded from $7 \%$ to $30 \%$ of the total catchment area during the past 60 years, and further expansion is planned. Wetlands are found near the outlet. Runoff from the area, both from subsurfacedrained agricultural land and surface runoff through storm drains from urban areas, is conducted to a main drainage ditch. The total length of the ditch studied here is about $4.5 \mathrm{~km}$. The ditch reach closest to the outlet overflows at high flows. In total, there are 13 culverts along the main ditch, ranging in diameter from 45 to $140 \mathrm{~cm}$. At several places, the ditch is in need of repair, and some culverts are broken or displaced. There are also problems with erosion within the water course, mostly in downstream reaches close to the outlet.

\section{MADRAS ASSESSMENT}

A visual evaluation of ditch status was made using MADRAS. The following parameters were included in the assessment: bank stability (erosion from surface runoff, mass failure, and seepage), over-widening or undercutting, and deposition. Based on the observations, the ditch was divided into six segments, each of which was allocated a score.

Bank stability was scored, ranging from 0 to 10 points, based on the occurrence of the following indicators: (1) bank erosion from surface runoff, (2) mass failure, and (3) groundwater intrusion. If no indicator was observed, the ditch segment was assessed as being in optimal condition and was awarded 0 points. If three indicators or $10 \%$ of the ditch segment were affected at any point, the ditch status was rated as very poor and was given 10 points.

Over-widening or undercutting of banks were assessed based on the following indicators: (1) bank evenly shaped across the ditch segment, with no undercutting visible; (2) one of the following indicators visible: irregular ditch shape, irregular channel width, vertical bank; and (3) two of the following indicators visible: irregular ditch shape, irregular channel width, vertical bank. If three indicators or $20 \%$ of the banks were undercut and had fallen into the channel, the segment was given 10 points.

Deposition was assessed based on the following indicators: (1) no significant deposition; (2) sediment depth exceeding on average $7.5 \mathrm{~cm}$; (3) sediment deposits in the channel; and (4) banks in the water channel. The first indicator was given 0 points, the second 3 points, the third 5 points, and the fourth 10 points.

The scores were added together to give a total score of 0 to 30 points. A ditch was considered to be in good condition if it had an overall score between 0 and 8 , while marginally affected ditches had scores within the range of 9 to 15 points. Affected ditches had scores between 16 and 20 points, while a ditch segment with a score of 21 points or more was considered to be in poor condition. The six ditch segments studied (A to $\mathrm{F}$ in fig. 1) represented different combinations of soils and sizes. Each segment length was equal to 30 times the ditch width, which was considered long enough to be representative. The length of the segments studied ranged between 45 and $120 \mathrm{~m}$. All six segments were evaluated according to MADRAS. In addition, observations were made on the degree of vegetation cover in the ditch reaches, surface erosion on adjacent land, culverts, and outlets.

\section{MEASUREMENTS AND ANALYSIS}

Ditch stability is highly dependent on soil texture and the forces to which the ditch cross-section is exposed. Soil physical properties are time-dependent and vary during the year depending on soil water content and the effects of wettingdrying and freezing-thawing.

\section{Particle Size Distribution}

In each ditch segment, soil samples were collected for analysis of particle size distribution of the ditch material and sediment deposits. Particle size distribution was determined with a laser diffraction particle size analyzer (LA-950, 


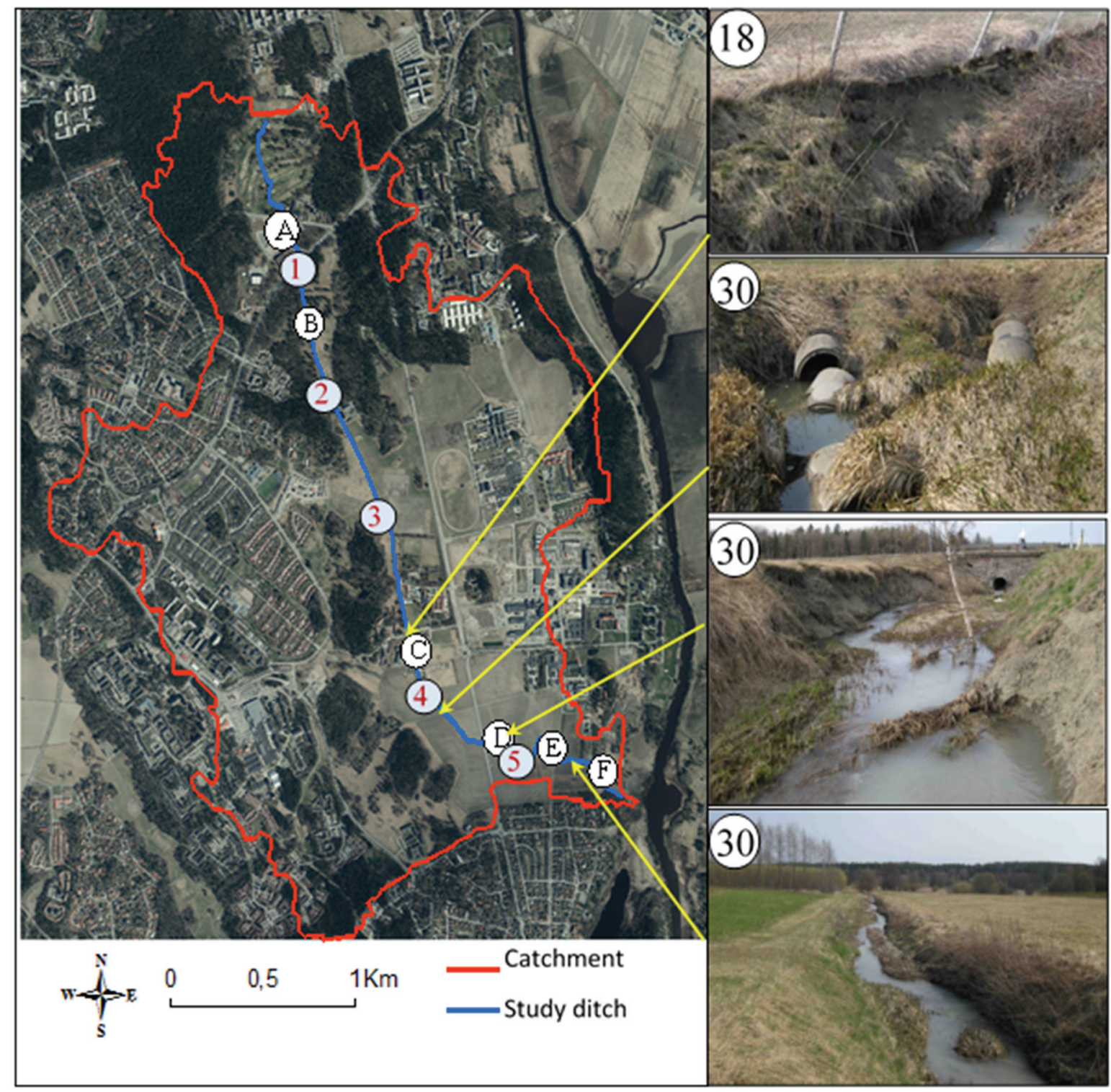

Figure 1. Map of study area and main ditch analyzed. Letters A to F indicate ditch segments from upstream (A) to downstream (F). Numbers 1 to 5 indicate flow accumulation points used in HEC-RAS simulations. The numbers in the four photos are total MADRAS scores.

Horiba Scientific, Kyoto, Japan) that uses a laser light scattering technique. With this technique, the size and number of particles are derived from the forward diffraction of a laser beam by the particles (Eshel et al., 2004). The LA-950 uses two light source wavelengths to achieve high-precision measurements (from $10 \mathrm{~nm}$ to $3 \mathrm{~mm}$ ) and Mie scattering theory for the calculations. This method has the advantage of high repeatability and short testing times, and only requires small soil samples.

A set of 18 soil samples from stable and unstable banks of segments $\mathrm{C}$ and $\mathrm{D}$ were collected at 0.8 to $1.2 \mathrm{~m}$ depth for determination of shear strength. Segment $\mathrm{D}$ was divided into two subsegments (D1 and D2) because some variability was observed in the field. All soil samples were first water-saturated and thereafter drained to a drainage equilibrium of 0.5 $\mathrm{m}$ water pressure in order to test the soil samples at a standardized moisture content and to mimic the sensitivity in field conditions.

\section{Unsaturated Direct Shear Strength}

Soil shear strength is commonly determined under saturated conditions. However, saturated conditions seldom exist in the field, and thus the test does not represent the most common state of the soil. In order to gain knowledge about the actual driver of erosion as mass movement, the soil shear strength under unsaturated conditions needs to be considered. In unsaturated conditions, soil matric suction affects the shear strength characteristics of the soil (Fredlund et al., 1996, 2012; Vanapalli et al., 1996) such that when the soil matric suction increases, the shear strength also increases. Unsaturated direct shear strength tests were therefore used to assess the soil shear strength under varying suction conditions.

The shear strength tests were carried out using an unsaturated shear testing system (VJT9540, VJ Tech Ltd., Reading, U.K.). The test started by applying a negative pressure of $5 \mathrm{kPa}$ (soil drained to $0.5 \mathrm{~m}$ ) and a selected vertical pressure 
(normal stress), which were both kept constant during the test. When the sample stopped draining and no further volume change occurred, the sample was exposed to shear stress at a rate of $0.01 \mathrm{~mm} \mathrm{~s}^{-1}$. Three normal stress levels $(20,60$, and $100 \mathrm{kPa}$ ), with three repetitions, were used to produce the soil shear strength, where $20 \mathrm{kPa}$ was equal to the moist soil weight at $1 \mathrm{~m}$ depth. One soil sample was used for each normal stress test. Each test took between 1.5 and 2 days, which was the shortest possible time to run the test without jeopardizing the reliability of the results. A longer test time is recommended but was considered impractical for this study.

\section{Critical Stress for Erosion}

Fluvial erosion refers to the detachment and transport of soil particles by the action of moving water. The rate at which the soil is detached and transported is usually modeled by the excess shear equation (Papanicolaou et al., 2006; Partheniades, 1965):

$$
\varepsilon=k_{d}\left(\tau-\tau_{c}\right)^{a}
$$

where $\varepsilon\left(\mathrm{m} \mathrm{s}^{-1}\right)$ is the fluvial erosion rate, $k_{d}\left(\mathrm{~m}^{2} \mathrm{~s} \mathrm{~kg}^{-1}\right)$ is an erodibility coefficient, $\tau(\mathrm{Pa})$ is the shear stress applied, $\tau_{c}(\mathrm{~Pa})$ is the critical shear stress, and $a$ is an empirically derived exponent usually assumed to be equal to 1 (Al-Madhhachi et al., 2013). The fluvial erosion rate is therefore characterized by the amount of shear stress that the soil particles at the surface can withstand before experiencing detachment and transport. Fluvial erosion occurs when this critical value of shear stress is exceeded by the action of moving water (Tolhurst et al., 1999).

Critical stress for erosion was assessed using a cohesive strength meter (CSM, Partrac, Glasgow, U.K.). The device directs a water jet onto a $2 \mathrm{~cm}$ layer of water that is in direct contact with the soil surface and records: (1) the pressure of the water exerted from the jet and (2) the turbidity of the resulting suspended sediment. An on-board processor records these variables at fixed time intervals depending on the chosen routine. The turbidity of the suspended sediment is measured as light transmission recorded by an integrated sensor. A rapid decay in light transmission indicates erosion. The CSM data can be used to obtain the critical shear stress $\left(\tau_{c}\right)$ indirectly (Grabowski et al., 2010). The CSM approach has recently been used in agricultural watersheds for indirect measurement of soil critical shear stress (Singh and Thompson, 2016).

Twelve undisturbed soil samples were taken at a depth of 0.8 to $1.2 \mathrm{~m}$ in segments C and D (D1 and D2), with three samples used in each test. The samples were water-saturated and thereafter drained to a drainage equilibrium of $0.5 \mathrm{~m}$ water pressure in order to bring the soil samples to a standard moisture content before the CSM test. The test was started with a low pressure, which was gradually increased. At each step, a measurement of transmittance was conducted.

At present, there is no standard procedure for CSM testing of the specific types of soil encountered in the study area. Therefore, we used the obtained values only for comparison of soil sensitivity to the water jet stress. We applied four different CSM test routines. The first routine, called Fine 1, had a jet fired for $1 \mathrm{~s}$ and data logged for $3 \mathrm{~s}$. The test started with $0.69 \mathrm{kPa}$, and the pressure was increased by $0.69 \mathrm{kPa}$ steps to
$15.86 \mathrm{kPa}$, by $2.07 \mathrm{kPa}$ steps to $41.37 \mathrm{kPa}$, and thereafter by $13.79 \mathrm{kPa}$ steps to $413.67 \mathrm{kPa}$. The second routine, called Mud 9, had a jet fired for $1 \mathrm{~s}$ and data logged for $30 \mathrm{~s}$. The test started with $3.45 \mathrm{kPa}$, and the pressure was increased by 3.45 $\mathrm{kPa}$ steps to $34.47 \mathrm{kPa}$ and thereafter by $0.69 \mathrm{kPa}$ steps to $413.69 \mathrm{kPa}$. The third routine, called Sand 17, had a jet fired for $1 \mathrm{~s}$ and data logged for $3 \mathrm{~s}$. The test started with $13.79 \mathrm{kPa}$, and the pressure was increased by $13.79 \mathrm{kPa}$ steps to 413.69 $\mathrm{kPa}$. The fourth routine, called Sand 1 , had a jet fired for $0.3 \mathrm{~s}$ and data logged for $3 \mathrm{~s}$. The test started with $2.07 \mathrm{kPa}$, and the pressure was increased by $2.07 \mathrm{kPa}$ steps to $82.74 \mathrm{kPa}$.

Mud 9 had the longest duration, as it included several jet fires with different pressure increments, followed by Fine 1 and Sand 17. Sand 1 had the shortest duration and only reached a jet pressure of $82.74 \mathrm{kPa}$. Because different numbers of jet fires were applied, as well as different pressure steps and durations, the four tests are not comparable. It is important to note that the actual pressure exerted by the water flow on the soil surface was lower than the pressure of the jet because the water jet was not acting directly on the soil surface.

\section{HEC-RAS DATA MODEL}

HEC-RAS was used to model how changes in ditch geometry, water flow rate, and ditch status affected the water level in the ditch. Three scenarios with different land uses (representing the years 1952, 2012, and 2020) were examined, the latter using detailed future development plans. Maps of land use in the different years were used to estimate changes in runoff conditions from installation of the ditch to the present day and possible changes in the future. The hydraulic design procedure involved evaluating the existing conditions for each channel using HEC-RAS.

HEC-RAS estimates the flow in natural and man-made channels using the one-dimensional Manning equation (Chow, 1964). Energy losses are evaluated by friction and contraction/expansion coefficients multiplied by the change in velocity head. Where the water surface profile varies rapidly, the momentum equation is used. By including these equations, HEC-RAS can handle hydraulic jumps and, e.g., the hydraulics of bridges, and evaluate stream profiles. HEC-RAS can also be used to determine the effects of various obstructions such as bridges, culverts, and structures in the flood plain. The software provides a number of outcomes, but in this article we only present the water level, the critical level for subcritical flow, the water velocity, and the average shear forces of the flowing water in different segments of the channel, with high values indicating an increased risk of erosion.

\section{RESULTS AND DISCUSSION}

Comparisons of the measured ditch profile at 25 locations along its length against the original blueprints for the ditch from 1974 showed that the ditch had eroded in various places and had become both wider and deeper. Figure 2 shows the cross-sections as designed in 1974 and the same cross-sections under current conditions. The cross-sections under current conditions were used as input data to evaluate the current ditch capacity in HEC-RAS (table 1). 

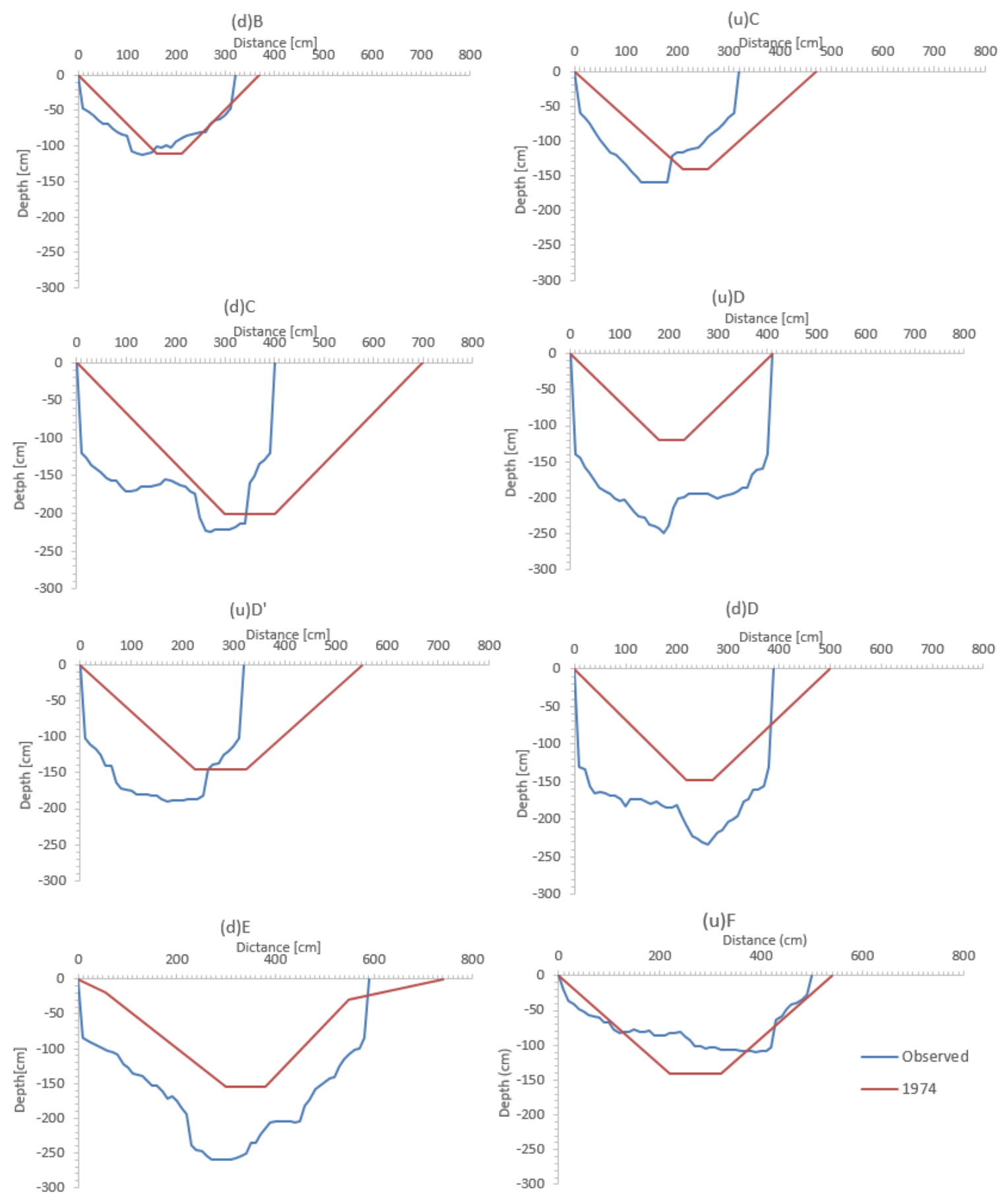

Figure 2. Cross-sections as designed in 1974 and observed under current conditions. The capital letters refer to the ditch segments (B to F) included in the MADRAS assessment. The letters in parentheses show the relative position to the closest ditch segment, where $(u)=u p s t r e a m$ and $(d)=$ downstream. Positions (u)D and (u) $D^{\prime}$ are both upstream of segment $D$.

\section{MADRAS ASSESSMENT}

The total scores for all ditch segments studied (A to F) are presented in figure 1 and table 2 . In segment $\mathrm{A}$, the channel banks were almost unaffected by erosion. The vegetation along the ditch was acceptable with regard to erosion control. Grass covered most of the bank surface but was somewhat sparser on the eastern side. According to MADRAS, this segment of the ditch received 0 points with respect to bank stability, 3 points for over-widening or undercutting of the banks, and 0 points for sediment deposition. This gave a total score of 3 .
In segment $\mathrm{B}$, the channel bank stability was rated relatively good, despite signs of minor bank failure. According to MADRAS, the ditch was given 5 points with respect to bank stability, 3 points for over-widening or undercutting of the banks, and 0 points for sediment deposition. This gave a total score of 8 .

In segment $\mathrm{C}$, the channel bank stability was less good. According to MADRAS, the ditch was given 5 points with respect to bank stability, 10 points with respect to over-widening or undercutting of the banks, and 3 points with respect to sediment deposition. This gave a total score of 18 points. 
Table 1. Calculated drain flows for 1952, 2012, and 2020 land uses at flow accumulation points 1 through 5 (fig. 1) and HEC-RAS-simulated average flow shear and average water velocity for the 2012 land use.

\begin{tabular}{|c|c|c|c|c|c|}
\hline \multirow{3}{*}{$\begin{array}{c}\text { Flow } \\
\text { Accumulation } \\
\text { Point }\end{array}$} & \multirow{3}{*}{$\begin{array}{c}1952 \\
\text { Flow } \\
\left(\mathrm{m}^{3} \mathrm{~s}^{-1}\right)\end{array}$} & \multirow{3}{*}{$\begin{array}{c}2012 \\
\text { Flow } \\
\left(\mathrm{m}^{3} \mathrm{~s}^{-1}\right)\end{array}$} & \multirow{3}{*}{$\begin{array}{c}2020 \\
\text { Flow } \\
\left(\mathrm{m}^{3} \mathrm{~s}^{-1}\right)\end{array}$} & \multicolumn{2}{|c|}{ HEC-RAS 2012} \\
\hline & & & & Flow & Water \\
\hline & & & & $\begin{array}{c}\text { Shear } \\
\left(\mathrm{N} \mathrm{m}^{-2}\right)\end{array}$ & $\begin{array}{c}\text { Velocity } \\
\left(\mathrm{m} \mathrm{s}^{-1}\right)\end{array}$ \\
\hline Upstream 1 & & & & 14.96 & 0.80 \\
\hline 1 & 0.30 & 0.30 & 0.60 & - & - \\
\hline Downstream 1 & & & & 14.12 & 0.78 \\
\hline Upstream 2 & & & & 6.09 & 0.58 \\
\hline 2 & 0.44 & 0.44 & 1.20 & - & - \\
\hline Downstream 2 & & & & 0.76 & 0.19 \\
\hline Upstream 3 & & & & 14.13 & 0.81 \\
\hline 3 & 0.66 & 1.14 & 2.05 & - & - \\
\hline Downstream 3 & & & & 5.54 & 0.52 \\
\hline Upstream 4 & & & & 19.34 & 1.01 \\
\hline 4 & 1.04 & 3.49 & 3.80 & - & - \\
\hline Downstream 4 & & & & 13.79 & 0.71 \\
\hline Upstream 5 & & & & 9.94 & 0.66 \\
\hline 5 & 1.10 & 4.78 & 5.00 & - & - \\
\hline Downstream 5 & & & & 7.09 & 0.58 \\
\hline
\end{tabular}

Table 2. Results of MADRAS assessment in segments A to $F$.

\begin{tabular}{ccccccc}
\hline & \multicolumn{6}{c}{ Ditch Segment } \\
\cline { 2 - 7 } & $\mathrm{A}$ & $\mathrm{B}$ & $\mathrm{C}$ & $\mathrm{D}$ & $\mathrm{E}$ & $\mathrm{F}^{[\mathrm{a}]}$ \\
\hline Bank stability & 0 & 5 & 5 & 10 & 10 & - \\
Over-widening or undercutting & 3 & 3 & 10 & 10 & 10 & - \\
Sediment deposition & 0 & 0 & 3 & 10 & 10 & - \\
Total score & 3 & 8 & 18 & 30 & 30 & - \\
\hline
\end{tabular}

[a] Not possible to score because segment F was extremely degraded.

Segment $\mathrm{D}$ had a vertical bank with no vegetation cover. The banks were very unstable, and the original design of the ditch had been greatly altered. According to MADRAS, the ditch was given 10 points with respect to bank stability, 10 points with respect to over-widening or undercutting of the banks, and 10 points for sediment deposition. This resulted in a total score of 30 points, the maximum score obtainable.

Segment $E$ had a channel width that varied between 0.8 and $2.4 \mathrm{~m}$, and $50 \%$ of the segment showed signs of being influenced by bank collapse. The ditch geometry was affected by bank failure along the entire segment. According to MADRAS, the ditch was given 10 points with respect to bank stability, 10 points with respect to over-widening or undercutting of the banks, and 10 points with respect to sediment deposition. The overall score for segment $\mathrm{E}$ was thus 30 points.
In segment $\mathrm{F}$, the banks were missing entirely, so it was not possible to assess them with MADRAS. A channel was observed, but the water flowed freely over a large area.

Based on our implementation experiences, MADRAS is a good, systematic tool for evaluating the state of agricultural ditches. However, it could be helpful to expand the scale of scoring in order to provide more sensitivity. In addition, MADRAS was educational for our understanding of ditch design, ditch maintenance, potential degradation processes, and necessary remediation measures.

\section{SoIL Physical Measurements}

The particle size distribution of soil samples from both stable and unstable banks in segments $\mathrm{C}$ and $\mathrm{D}$ is shown in figure 3 . In general, the soils seemed to have a similar texture, with slightly coarser soil in the unstable banks, particularly in segment D. Colloidal clay content was $4.0 \%$ to $5.5 \%$, clay content was $29.5 \%$ to $32.5 \%$, silt content was $51.5 \%$ to $56.6 \%$, and sand content was $11.0 \%$ to $19.0 \%$.

The shear strength measurements revealed clear differences between unstable banks (no vegetation) and stable banks (with vegetation) in segments C and D1 (fig. 4). Shear strength was also lower in unstable banks than in stable banks, particularly at a normal pressure of $20 \mathrm{kPa}$ (the soil's own weight) and $60 \mathrm{kPa}$. These differences continued to vary between sites when the normal pressure was increased. Plant roots had a very strong influence on soil shear strength, but the effect of vegetation differed at different locations for reasons that were not possible to investigate in this study but that may be related to differences in vegetation type, and thereby differences in root development and root density.

The CSM measurements proved to be dependent on the test procedure used (fig. 5); therefore, the results were used only for comparison and as a guideline for further development of the test. Many samples showed a decrease in transmittance, followed by an increase. However, the pressure used at the beginning of the tests was very low, and therefore possible explanations could be loose soil particles on the surface of the soil sample before starting the test or dirt in the sensor. This will be carefully assessed when improving the test routines. In all tests, the soil in the bank at segment D1 proved to be the

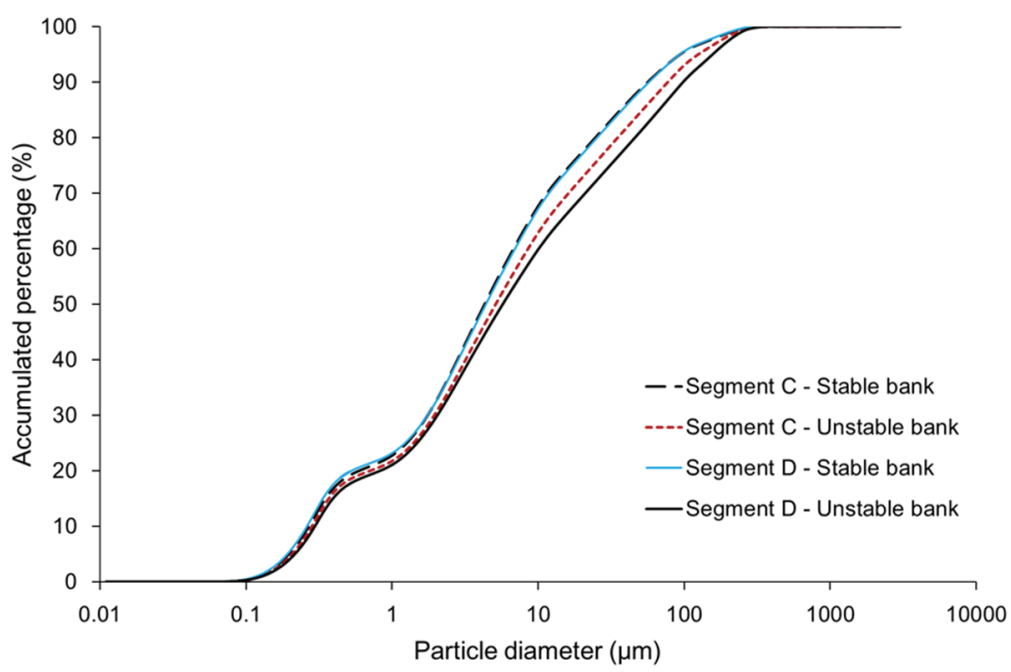

Figure 3. Particle size distribution of soil samples from stable and unstable banks in segments $C$ and $D$. 

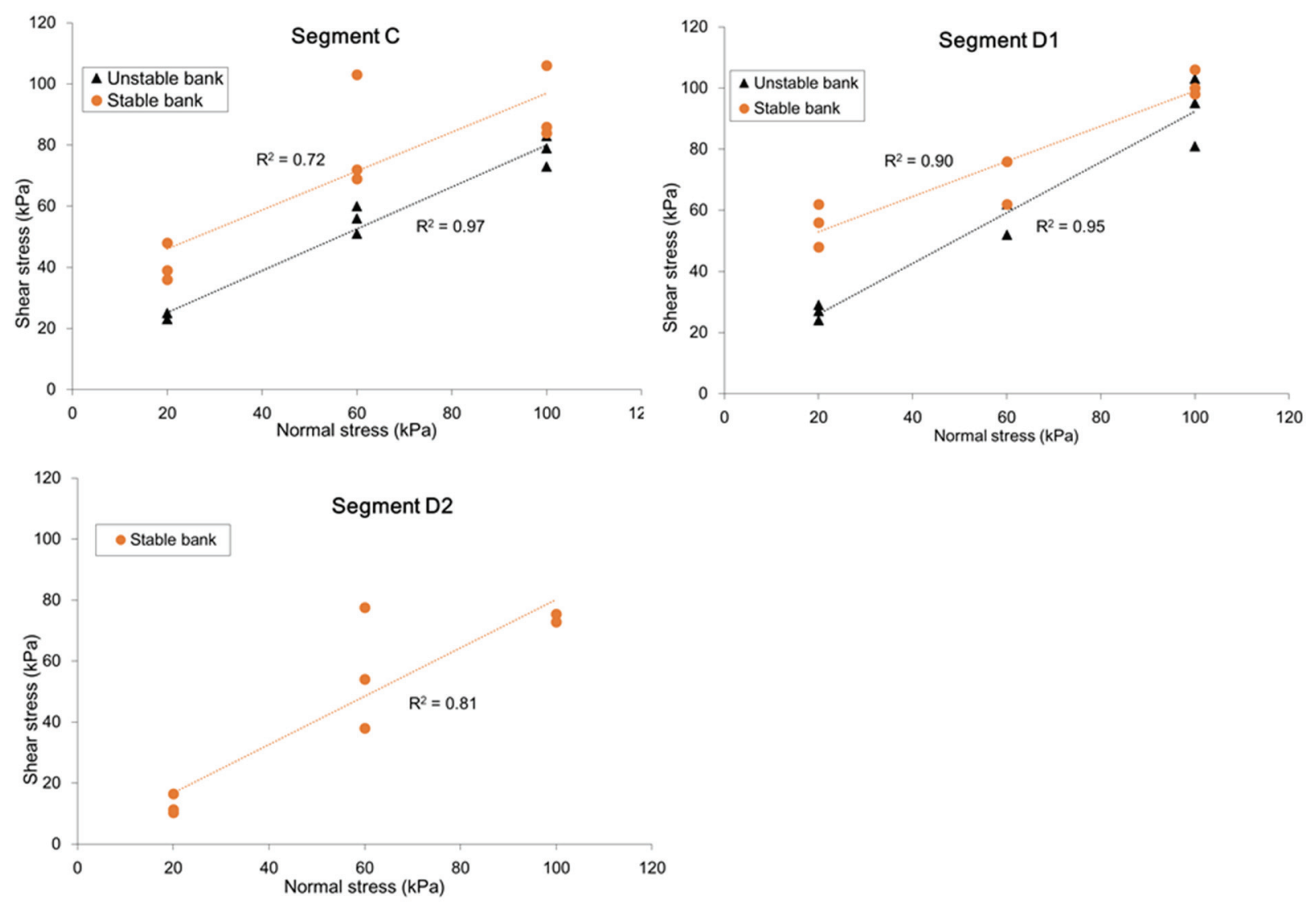

Figure 4. Shear strength of soil samples taken at $1 \mathrm{~m}$ depth from stable and unstable banks in segments C, D1, and D2. The normal stresses applied were 20,60 , and $100 \mathrm{kPa}$.
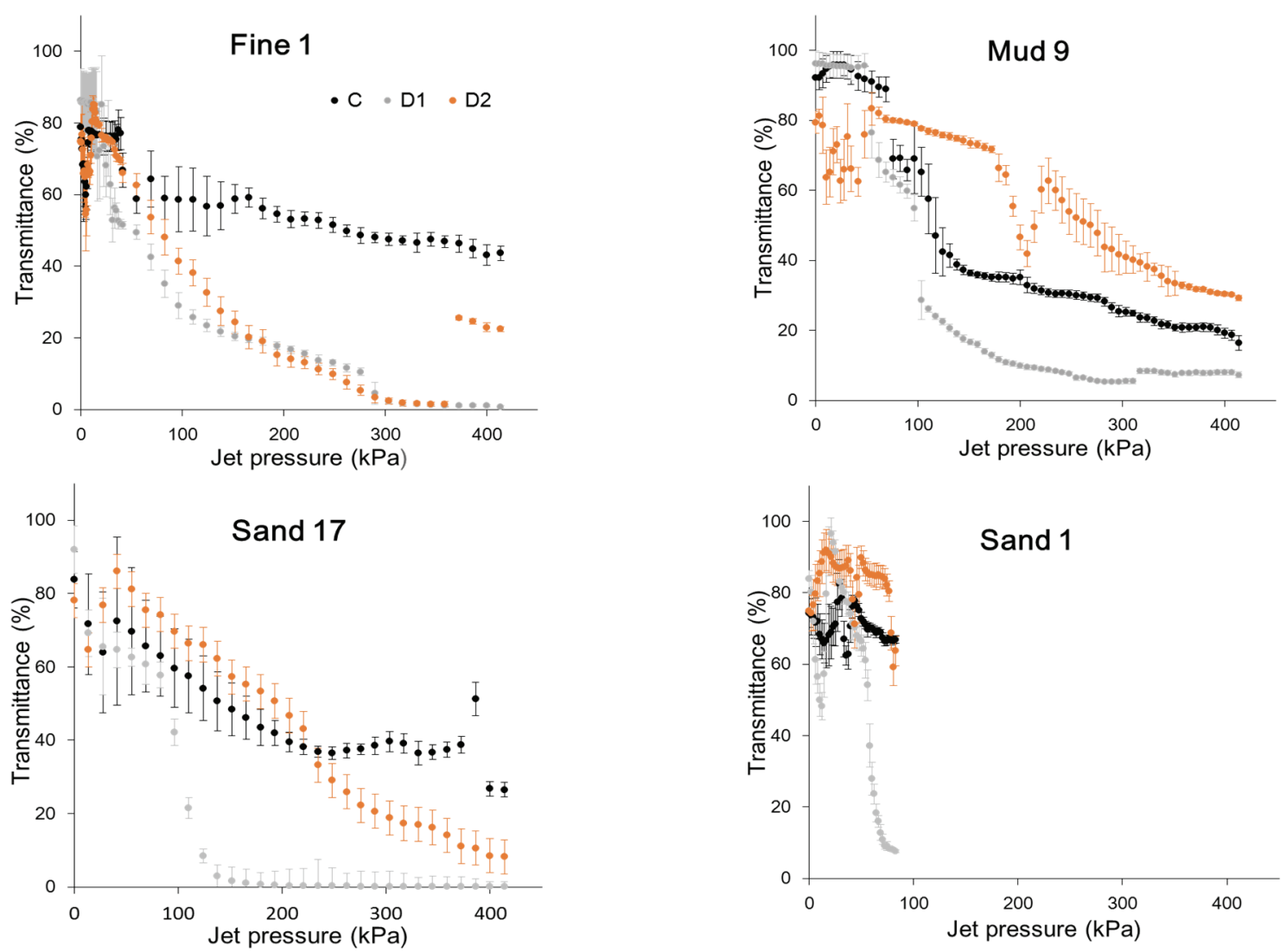

Figure 5. Cohesive strength meter (CSM) tests of bank soil samples from segments C, D1, and D2. Bars indicate the standard deviation of three replicates. 
most sensitive, with a clear drop in transmittance observed between 30 and $100 \mathrm{kPa}$. For segments C and D2, different results were obtained when using different tests, with a decrease in transmittance at $100 \mathrm{kPa}$. In all tests, the variability in the results for the three replicates (bars in fig. 5) was relatively low, which indicates that individual tests have the capacity to yield similar results from a similar soil sample.

At present, the measured values are relative values. Work on relating the applied jet pressure to the actual pressure exerted at the soil surface is ongoing. Additionally, there is a need to determine the relationship between the jet pressure and the pressure of flowing water at different velocities.

\section{ASSESSMENT OF FLOW IMPACT WITH HEC-RAS}

Flow calculations were made with the time-area method (Svenskt Vatten, 2004) according to the land use in 1952, 2012, and future development plans for 2020. The results showed that the predicted flow has increased by a factor of 4 since 1952 and will probably keep increasing with the new development plans, although not as dramatically as in the past (table 1). Based on the calculated flows and the measured ditch profiles, the water levels in the ditch were simulated in HEC-RAS. The results showed that the ditch, as constructed in 1974, was well-designed for the flow calculated from the land use in 1952. However, the conversion from natural land to hard surfaces in the catchment has increased. Today, some culverts are too small for the current flows and, if the flow rates continue to increase, the situation will be further aggravated in the future.

In order to evaluate the current ditch capacity in HECRAS, simulated 30 min rain intensities with a return period of 10 years were used as the design flow under the land use in 2012. Upstream, in the first segment of the ditch, the flow was relatively low and increased slightly, from 0.30 to 0.44 $\mathrm{m}^{3} \mathrm{~s}^{-1}$, at accumulation point 2 (fig. 1). As more segments started to contribute to flow accumulation in the ditch, the flow increased to $1.14 \mathrm{~m}^{3} \mathrm{~s}^{-1}$ at accumulation point 3 . Farther downstream, contributions of rapid stormwater flow from urban settlements were included at accumulation point 4 , resulting in a total flow of $3.49 \mathrm{~m}^{3} \mathrm{~s}^{-1}$. At accumulation point 5 , the flow increased to $4.78 \mathrm{~m}^{3} \mathrm{~s}^{-1}$. Flow values for the different land use scenarios $(1952,2012$, and 2020) are shown in table 1 . Only land use was considered for future flows, but the predicted change to more extreme weather conditions will probably increase the calculated flows.

In general, areas classified as degraded according to MADRAS did not have higher values of hydraulic shear in the HEC-RAS simulations compared with less degraded areas (Joel et al., 2015). This means that the force exerted by the flowing water in the channel bed and on the channel banks was not high enough to cause the effects observed in the MADRAS evaluation. Therefore, the flow rate alone cannot explain the degradation of these ditch segments. However, the surface runoff observed in the MADRAS assessment may explain the observed level of degradation to some extent.

\section{CONCLUSIONS}

MADRAS proved to be a suitable tool for rapid assessment of stability problems in ditches. The HEC-RAS simulations were a good complement to MADRAS for assessing how changes in land use affected the hydraulic load in ditches and for highlighting bottlenecks in the system. However, the hydraulic load was not sufficient to explain the degradation observed in some ditch segments. The decision to use MADRAS and/or HEC-RAS as tools for assessing ditch status and bank stability should be based on the purpose of the assessment and the skills of the analyst. MADRAS is a user-friendly tool for rapid detection of ditch stability problems, while HEC-RAS provides an assessment of the hydraulic load in different ditch segments. Measurements of soil shear strength were a good aid in understanding the existing degradation. Banks with vegetation clearly had higher soil shear strength, and therefore vegetating ditch edges can be a potential stabilizing measure. However, studies are needed to assess how different vegetation types can contribute optimal root distribution without increasing maintenance requirements and interfering with ditch functionality. Assessment of sensitivity to erosion with CSM tests can be useful for characterizing the susceptibility of soil to erosion by flowing water, at least in comparative terms, if the correct test procedure is chosen and if the CSM values can be directly related to the actual pressure of flowing water needed for eroding the soil. The impacts of freeze-thaw and wettingdrying cycles on soil critical shear stress of the channel banks for erosion by flowing water should also be considered.

\section{ACKNOWLEDGEMENTS}

The authors wish to thank the Swedish Farmers' Foundation for Agricultural Research for financial support for this project (Project No. V1260007). The Swedish International Development Agency (SIDA) is also acknowledged for financial support. We also want to thank Dr. Mary McAfee for giving valuable advice and suggestions on the manuscript.

\section{REFERENCES}

Alexandersson, H., Karlstrom, C., \& Larsson-McCann, S. (1991). Temperaturen och nederbörden i Sverige 1961-90, Referensnormaler. SMHI Meteorologi 81. Norrköping, Sweden: Swedish Meteorological and Hydrological Institute.

Al-Madhhachi, A. T., Hanson, G. J., Fox, G. A., Tyagi, A. K., \& Bulut, R. (2013). Measuring soil erodibility using a laboratory “Mini” JET. Trans. ASABE, 56(3), 901-910. https://doi.org/10.13031/trans.56.9742

Chow, V. T. (1964). Runoff. In V. T. Chow (Ed.), Handbook of applied hydrology (pp. 21-57). New York, NY: McGraw-Hill.

Constantine, C. R., Dunne, T., \& Hanson, G. J. (2009). Examining the physical meaning of the bank erosion coefficient used in meander migration modeling. Geomorphology, 106(3), 242-252. https://doi.org/10.1016/j.geomorph.2008.11.002

Eshel, G., Levy, G. J., Mingelgrin, U., \& Singer, M. J. (2004). Critical evaluation of the use of laser diffraction for particle-size distribution analysis. SSSA J., 68(3), 736-743. https://doi.org/10.2136/sssaj2004.7360 
Fausey, N. R., Nolte, B. H., \& Beathard, P. S. (1982). Subsurface drainage maintenance in Ohio. Trans. ASAE, 25(4), 997-1001. https://doi.org/10.13031/2013.33654

Fredlund, D. G., Rahardjo, H., \& Fredlund, M. D. (2012). Unsaturated soil mechanics in engineering practice. Hoboken, NJ: John Wiley \& Sons. https://doi.org/10.1002/9781118280492

Fredlund, D. G., Xing, A., Fredlund, M. D., \& Barbour, S. L. (1996). The relationship of the unsaturated soil shear to the soilwater characteristic curve. Canadian Geotech. J., 33(3), 440448. https://doi.org/10.1139/t96-065

Grabowski, R. C., Droppo, I. G., \& Wharton, G. (2010). Estimation of critical shear stress from cohesive strength meter-derived erosion thresholds. Limnol. Oceanogr. Methods, 8(12), 678-685. https://doi.org/10.4319/lom.2010.8.678

Joel, A., Wesstrom, I., \& Messing, I. (2015). A tool for assessing the status of drainage ditches and the need for remedial measures. Acta Agriculturae Scandinavica B, 65(supp. 1), 100109. https://doi.org/10.1080/09064710.2014.996589

Kallio, R., Ward, A., D'Ambrosio, J., \& Witter, J. D. (2010). A decade later: The establishment, channel evolution, and stability of innovative two-stage agricultural ditches in the midwest region of the United States. ASABE Paper No. IDSCSBE100209. St. Joseph, MI: ASABE. https://doi.org/10.13031/2013.32159

Knapen, A., Poesen, J., Govers, G., Gyssels, G., \& Nachtergaele, J. (2007). Resistance of soils to concentrated flow erosion: A review. Earth-Sci. Rev., 80(1), 75-109. https://doi.org/10.1016/j.earscirev.2006.08.001

Lawler, D. M. (1993). The measurement of river bank erosion and lateral channel change: A review. Earth Surf. Proc. Landforms, 18(9), 777-821. https://doi.org/10.1002/esp.3290180905

Magner, J. A., Hansen, B. J., Anderson, C., Wilson, B. N., \& Nieber, J. L. (2010). Minnesota agricultural ditch reach assessment for stability (MADRAS): A decision support tool. ASABE Paper No. IDS-CSBE100229. St. Joseph, MI: ASABE. https://doi.org/10.13031/2013.32170

Mehta, A. J., \& Partheniades, E. (1982). Resuspension of deposited cohesive sediment beds. Proc. 18th Intl. Conf. Coastal Eng. Reston, VA: ASCE. https://doi.org/10.1061/9780872623736.095

Papanicolaou, A. N., Rinaldi, M., Dey, S., \& Mazumdar, A. (2006). Research issues for riverine bank stability analysis in the 21st century. IIHR Technical Report No. 457. Iowa City, IA: University of Iowa, IIHR Hydroscience and Engineering.

Partheniades, E. (1965). Erosion and deposition of cohesive soils. $J$. Hydraul. Div., 91(1), 105-139.

Singh, H. V., \& Thompson, A. M. (2016). Effect of antecedent soil moisture content on soil critical shear stress in agricultural watersheds. Geoderma, 262, 165-173. https://doi.org/10.1016/j.geoderma.2015.08.011

Svenskt Vatten. (2004). Dimensionering av allmänna avloppsvattenledningar. Publikation P90. Stockholm, Sweden: Svenskt Vatten AB.

Tolhurst, T. J., Black, K. S., Shayler, S. A., Mather, S., Black, I., Baker, K., \& Paterson, D. M. (1999). Measuring the in situ erosion shear stress of intertidal sediments with the cohesive strength meter (CSM). Estuarine Coastal Shelf Sci., 49(2), 281294. https://doi.org/10.1006/ecss.1999.0512

USACE. (2010). HEC-RAS river analysis system: Hydraulic reference manual. Version 4.1. Davis, CA: U.S. Army Corps of Engineers, Hydrology Engineering Center.

Vanapalli, S. K., Fredlund, D. G., Pufahl, D. E., \& Clifton, A. W. (1996). Model for the prediction of shear strength with respect to soil suction. Canadian Geotech. J., 33(3), 379-392.

https://doi.org/10.1139/t96-060 